Myers, J. E. Willse, J. T., \& Villalba, J. A. (2011). Promoting Self-Esteem in Adolescents: The Influence of Wellness Factors. Journal of Counseling \& Development. 89(1), p. 28-36 dx.doi.org/10.1002/j.1556-6678.2011.tb00058.x

\title{
Promoting Self-Esteem in Adolescents: The Influence of Wellness Factors
}

\author{
Jane E. Myers, John T. Willse, and José A. Villalba
}

To assess the extent to which holistic wellness factors are predictive of self-esteem, the authors administered the Coopersmith Self-Esteem Inventories, School Form (Coopersmith, 2002), and the Five Factor Wellness Inventory (Myers \& Sweeney, 2005a) to 225 adolescents ages 15 to 17 years. Wellness factors (Coping Self, Social Self, and Creative Self) explained a significant portion of the variance in components of self-esteem (General Self-Esteem, Home-Parents Self-Esteem, and School-Academic Self-Esteem). Implications for counselors and for further research are considered.

Self-esteem, the feelings individuals have about themselves (Bosson, Brown, Zeigler-Hill, \& Swann, 2003), is among the most widely researched topic in psychology and counseling (Searcy, 2007). Self-esteem has been directly connected to individuals' social network, their activities, and what they hear about themselves from others (e.g., Kernis, 2003). Multiple studies have linked a positive sense of self-esteem to factors such as psychological health (González, Casas, \& Coenders, 2007; Keyes, 2006), mattering to others (Marshall, 2001), and both body image and physical health (Kostanski \& Gullone, 1998). Conversely, low self-esteem has been linked to outcomes such as depression (MacPhee \& Andrews, 2006), health problems (Stinson et al., 2008), and antisocial behavior (Niregi, 2006). There is some disagreement in the literature as to whether self-esteem is a stable or changing characteristic; however, recent research using cross-sectional data on more than 326,600 persons suggests that self-esteem changes over the life span and is particularly critical during adolescent development, when it is likely to decline (Robins, Trzesniewski, Tracy, Gosling, \& Potter, 2002).

Self-esteem during adolescence is affected by a variety of factors, such as age, race, ethnicity, puberty, body weight, involvement in physical activities, and gender (McLoed \& Owens, 2004; Powell, 2004). Both boys and girls experience declines in global self-esteem during adolescence, and in contrast to boys' self-esteem, girls' self-esteem does not increase until young adulthood (Twenge \& Campbell, 2001). Self-esteem also has been studied as a multidimensional construct, including social and academic components in addition to studies of self-esteem in the context of home and school (e.g., Coopersmith, 2002). For example, Wastlund, Norlander, and Archer (2001) found that girls in Asia, Australia, and the United States reported higher academic self-concepts than boys did, whereas boys reported higher nonacademic and total self-concept than girls did.

Stinson et al. (2008) found that lower self-esteem in adolescents is predictive of poor health, and the authors presented a model to explain this relationship as a result from poor quality social bonds. Studies such as this underscore the holistic nature of facets of adolescent functioning and the need to better understand the interaction of factors that affect positive development and well-being. Wellness models based in counseling emphasize these interactions and provide a structure for developing strength-based counseling interventions (Myers \& Sweeney, 2008). The importance of such interventions during adolescence lies in helping young persons choose healthy behaviors as a foundation for healthy functioning across the life span (Dixon Rayle \& Hartwig Moorhead, 2005; Myers \& Sweeney, 2005b). Although virtually all wellness models include attention to self-worth in relation to wellness, studies examining the relationship of wellness factors to self-esteem among adolescents have not been conducted.

The present study was undertaken to determine the extent to which wellness factors are predictive of components of self-esteem in adolescents. We hypothesized that the determination of these relationships would result in identification of a path model to guide both research and counseling practice. Counselors often use wellness models as a foundation for both developmental and remedial interventions (e.g., Myers \& Sweeney, 2005b). An understanding of the relationship between wellness and self-esteem could enhance the effectiveness of such interventions, and thus help counselors promote positive self-esteem to counter the seemingly normative declines in this characteristic during the adolescent years. A brief review of the wellness model, research using the model with children and adolescents, and how the model is used for strength-based interventions is provided as further context for this study.

\section{The Indivisible Self: An Evidence-Based Model for Wellness Counseling With Adolescents}

The Wheel of Wellness, first introduced by Sweeney and Witmer (1991), was the first theoretical model of wellness based in counseling theory. It is an integrative model based on Adler's individual psychology and cross-disciplinary research on characteristics of healthy people who live longer and with a higher quality of life. The Wheel of Wellness (Myers \& Sweeney, 2005c) includes five interrelated life tasks: spiri-

Jane E. Myers and José A. Villalba, Department of Counseling and Educational Development, and John T. Willse, Department of Educational Research and Measurement, University of North Carolina at Greensboro. Correspondence concerning this article should be addressed to Jane E. Myers, Department of Counseling and Educational Development, University of North Carolina at Greensboro, PO Box 26170, Greensboro, NC 27402 (e-mail: jemyers@ uncg.edu).

(C) 2011 by the American Counseling Association. All rights reserved. 
tuality, self-direction, work and leisure, friendship, and love and 12 subtasks of self-direction areas: sense of worth, sense of control, realistic beliefs, emotional awareness and coping, problem solving and creativity, sense of humor, nutrition, exercise, self-care, stress management, gender identity, and cultural identity (Myers, Sweeney, \& Witmer, 2000). Data collection and analysis over more than 12 years led to the development of a new evidence-based model of wellness, the Indivisible Self Model of Wellness (IS-Wel; Myers \& Sweeney, 2005a), which provides an alternative perspective for viewing wellness across the life span.

The IS-Wel model was developed through structural equation modeling of a large database (Hattie, Myers, \& Sweeney, 2004; Myers \& Sweeney, 2005b). As shown in Figure 1, the factor structure incorporates the 17 separate wellness dimensions first proposed in the theoretical Wheel of Wellness model as third-order factors, grouped according to five second-order factors, and one higher order wellness factor. The higher order wellness factor reflects the fact that the self is indivisible. The five second-order factors, the Creative Self, Coping Self, Social Self, Essential Self, and Physical Self, allow exploration of the meaning of wellness within the total self. The original components of the Wheel of Wellness are still present, but they are grouped within these five factors in a different manner than was proposed in the original structure of the Wheel of Wellness.

The importance of context, or systems, in understanding human behavior, has been well established. As noted earlier, environmental factors can operate for better or for worse in relation to individual wellness. Thus, the IS-Wel is both affected by and has an effect on the surrounding world through four contexts. Local contexts include interactions with and the central influences of those systems in which people live most often, that is, our families, neighborhoods, and communities. Institutional contexts - education, religion, government, and business and industry - affect people's lives in both direct and indirect ways. Global contexts, including politics, culture, global events, and the environment, are made more salient and personal through the influence of the media. The final context, chronometrical, reflects the recognition that people change over time in important ways. Wellness involves the acute and chronic effects of lifestyle behaviors and choices throughout an individual's life span.

It is important that each of the components of the IS-Wel model interacts with all others to contribute to holistic functioning. This interaction is supported by the factor structure, especially the single higher order factor, as well as research on the person-environment interaction reported recently by Bronfenbrenner (2007). These interactions may be for better or for worse, individually and collectively. In other words, changes in any one wellness area can contribute to enhancements or reductions in wellness in other areas.

The IS-Wel model has been used to develop strength-based counseling interventions for a variety of persons and groups. Successful interventions have been documented with children

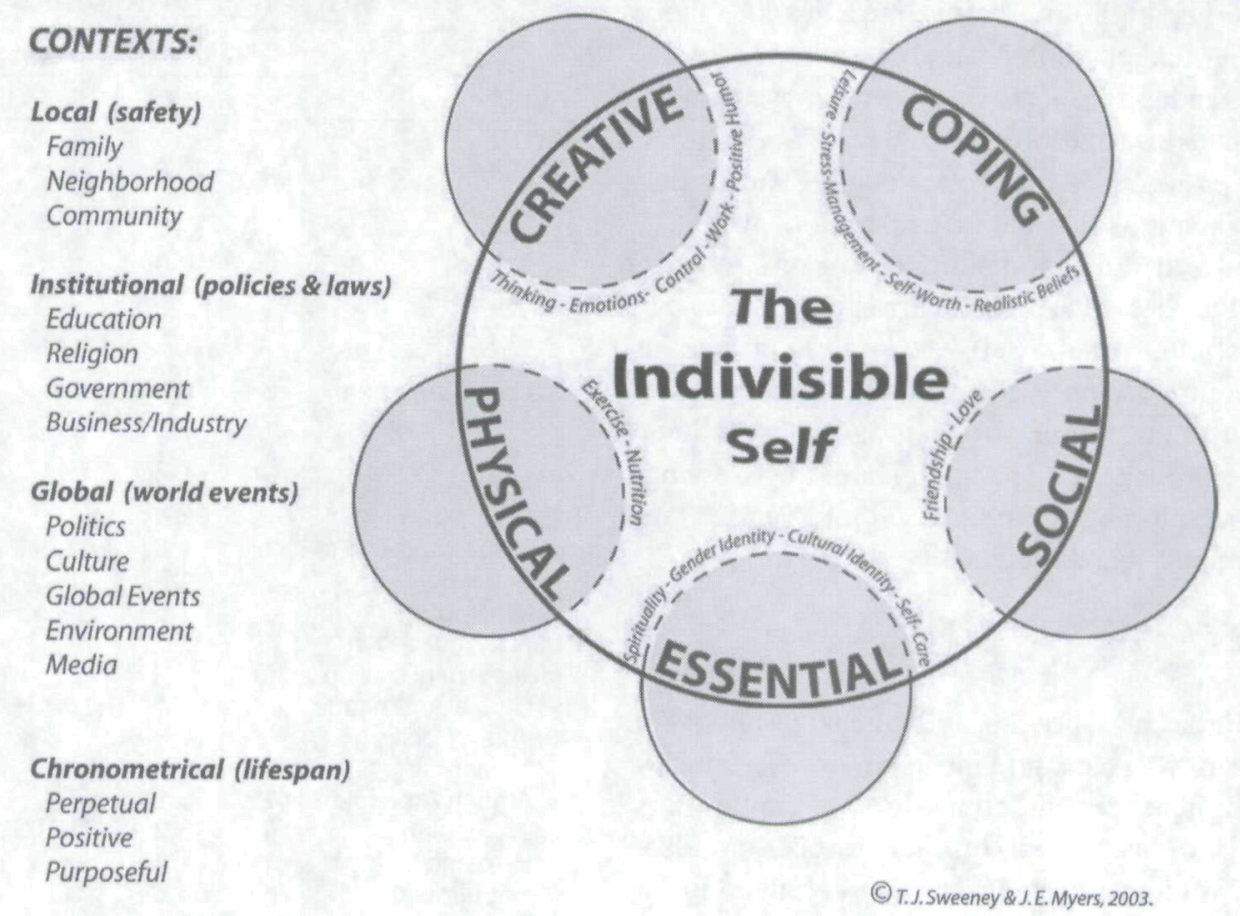

FIGURE 1

The Indivisible Self Model of Wellness

Note. Creative $=$ Creative Self; Coping $=$ Coping Self; Social $=$ Social Self; Essential $=$ Essential Self; Physical = Physical Self. From The Indivisible Self: An Evidence-Based Model of Wellness, by T. J. Sweeney and J. E. Myers, 2003, Greensboro, NC: Author. Copyright 2003 by T. J. Sweeney and J. E. Myers. Reprinted with permission. 
(Villalba \& Myers, 2008), adolescents (Makinson \& Myers, 2003), beginning college students (Choate \& Smith, 2003), and police officers (Tanigoshi, Kontos, \& Remley, 2008). What is common across these interventions is a focus on identifying strengths, positive assets, and resources related to each component of the wellness model and using these strengths to cope with life challenges.

In groups with elementary school children, for example, Villalba and Myers (2008) first assessed each child's wellness, and, then, through a series of groups, helped each child identify his or her areas of highest wellness or strengths and explore ways to use those strengths to help address areas of lower wellness. An example would be a child who selfreported low physical wellness and high social wellness. Building on successful peer relationships, this child could be helped to develop a wellness plan to increase exercise and fitness by engaging in fitness activities with friends. Someone who had high spiritual wellness and low social wellness could be encouraged to participate in group religious or spiritual activities and begin to develop relationships with others having common faith beliefs and practices.

Related more specifically to self-esteem issues, using the wellness paradigm allows counselors to identify whatever strengths a person may have, defined as areas of higher wellness (and everyone has areas of higher and lower wellness), and the person can then begin to use these strengths to build a stronger sense of self-esteem. An example would be helping someone who has high physical wellness explore their values and activities related to fitness and examine how other aspects of wellness are affected positively as a consequence. Helping clients recognize the holistic nature of wellness is just one means of promoting a focus on strengths, and, again, the underlying principle is that the interrelation of wellness components provides the foundation for focusing on strengths with the knowledge that areas of concern can begin to be addressed successfully. Because self-esteem is so critical in adolescence, and self-esteem is also an integral component of wellness, the inclusion of wellness models and interventions provides counselors with a useful paradigm both for assessing strengths and for developing strength-based interventions in schools and community-based counseling settings.

\section{Method}

School administrators at a private, independent school in the southeastern United States provided support by contacting staff, including teachers and counselors, to explain the proposed study. The local Parent-Teacher Association also provided support. Volunteer participants were recruited from intact ninth to 12 th grade classes. Parental consent was required for participation.

Of 225 students enrolled in ninth- to 12th-grades, 157 (70\% initial response rate) provided parental consent for participation. Instruments were completed online according to each student's own time and schedule. The instruments were made available during the 1st day of the 7th month (March) of a 9-month academic year, and the students had 4 weeks to complete the instruments. A total of 140 students fully completed all instruments, for a final response rate of $62 \%$; surveys from 22 students were discarded because of missing data.

As shown in Table 1, slightly under half of the participants were male (45.7\%). Most (84.3\%) identified as Caucasian, $7.1 \%$ were African American, 3.6\% were Asian/Pacific Islander, and $.7 \%$ each were Native American and Hispanic/ Latina/o. Ten were biracial (7.4\%), of which three identified most as Caucasian and three as African American. With regard to age, $28.1 \%$ of the participants were 17 years old, $50.4 \%$ were 16 years old, and $21.5 \%$ were 15 years old at the time of the study.

\section{Instruments}

Participants completed a demographic form and two instruments, the Five Factor Wellness Inventory (5F-Wel; Myers \& Sweeney, 2005a) and the Coopersmith Self-Esteem Inventories-School Form (CSEI-SF; Coopersmith, 2002).

Wellness. The 5F-Wel (Myers \& Sweeney, 2005a) was developed to assess the factors included in the IS-Wel. The IS-Wel is an evidence-based model grounded in Adlerian counseling theory that emphasizes the indivisibility of the self,

\section{TABLE 1}

\section{Demographic Descriptors for Male $(n=64)$ and Female $(n=76)$ Participants $(N=140)$}

\begin{tabular}{|c|c|c|c|c|c|c|}
\hline \multirow{2}{*}{ Variable } & \multicolumn{2}{|c|}{ Male } & \multicolumn{2}{|c|}{ Female } & \multicolumn{2}{|c|}{ Total } \\
\hline & $n$ & $\%$ & $n$ & $\%$ & $N$ & $\%$ \\
\hline \multicolumn{7}{|l|}{ Gender } \\
\hline Male & 64 & 40.8 & & & 64 & 45.7 \\
\hline Female & & & 76 & 48.4 & 76 & 54.3 \\
\hline \multicolumn{7}{|l|}{ Biracial } \\
\hline Yes & 7 & 10.9 & 3 & 3.9 & 10 & 7.2 \\
\hline No & 57 & 89.1 & 73 & 96.1 & 130 & 92.8 \\
\hline \multicolumn{7}{|l|}{$\begin{array}{l}\text { Primary cultural } \\
\text { identification }\end{array}$} \\
\hline Native American & 0 & 0.0 & 1 & 1.3 & 1 & 0.7 \\
\hline Asian/Pacific & & & & & & \\
\hline Islander & 2 & 3.1 & 3 & 3.9 & 5 & 3.6 \\
\hline African American & 4 & 6.3 & 6 & 7.9 & 10 & 7.1 \\
\hline Caucasian & 53 & 82.8 & 65 & 85.5 & 118 & 84.3 \\
\hline Hispanic/Latino/a & 1 & 1.6 & 0 & 0.0 & 1 & 0.7 \\
\hline Biracial & 3 & 4.7 & 1 & 1.3 & 4 & 2.9 \\
\hline Missing & 1 & 1.6 & 0 & 0.0 & 1 & 0.7 \\
\hline \multicolumn{7}{|l|}{$\begin{array}{l}\text { If biracial, secondary } \\
\text { cultural identification }\end{array}$} \\
\hline Native American & 2 & 3.1 & 2 & 2.6 & 4 & 2.9 \\
\hline \multicolumn{4}{|l|}{ Asian/Pacific } & 2.6 & & 2.1 \\
\hline African American & 2 & 3.1 & 0 & 0.0 & 2 & 1.4 \\
\hline Caucasian & 4 & 6.3 & 2 & 2.6 & 6 & 4.3 \\
\hline Hispanic/Latino/a & 1 & 1.6 & 0 & 0.0 & 1 & 0.7 \\
\hline Not biracial & 35 & 54.7 & 39 & 51.3 & 74 & 52.9 \\
\hline Missing & 19 & 29.7 & 31 & 40.8 & 50 & 35.7 \\
\hline \multicolumn{7}{|l|}{ Age } \\
\hline 15 & 6 & 9.4 & 18 & 23.7 & 24 & 15.3 \\
\hline 16 & 26 & 40.6 & 31 & 40.8 & 57 & 36.3 \\
\hline 17 & 19 & 29.7 & 14 & 18.4 & 33 & 21.0 \\
\hline Missing & 13 & 20.3 & 13 & 17.1 & 26 & 27.4 \\
\hline
\end{tabular}

Note. Percentages do not total $100 \%$ because of missing data. 
or what Adler called holism, and is based on a single, higher order wellness factor that includes all wellness components (Myers \& Sweeney, 2005c). The inclusion of all items in one strong factor supports the interactive nature of the wellness components (see Figure 1). The IS-Wel model also includes five second-order factors: Creative Self, Coping Self, Social Self, Essential Self, and Physical Self. Within these factors are grouped a set of 17 third-order factors (i.e., Thinking, Emotions, Control, Work, Positive Humor, Leisure, Stress Management, Self-Worth, Realistic Beliefs, Friendship, Love, Spirituality, Gender Identity, Cultural Identity, Self-Care, Exercise, and Nutrition). Only the first- and second-order factors were used in this study.

The 5F-Wel includes 73 attitudinal and behavioral statements (e.g., "I am an active person") that respondents rate using a 4-point Likert-type scale ranging from strongly agree (1) to strongly disagree (4). The instrument can be completed in approximately 15 minutes. Mean item ratings for each subscale are computed and modified using a linear transformation to make the subscales comparable, with each having a range from 25 to 100. Reliabilities for the subscales were reported by Myers and Sweeney (2005a) as follows: Total Wellness, .98; Creative Self, .96; Coping Self, .89; Social Self, .96; Essential Self, .95; and Physical Self, .90. In this study, the corresponding alpha coefficients were $.90, .89, .88, .89, .82$, and .87 , respectively.

Self-esteem. Self-esteem was measured using the CSEISF. Coopersmith hypothesized multiple aspects of selfesteem as a "central feature of the definition of self-esteem ... that one's overall appraisal of his/her self-esteem may not be reflective of one's self-appraisal under different roledefining conditions" (as cited in Sewell, 1985, p. 1). Thus, the 50-item CSEI-SF, which has been used extensively since 1981, measures children's "attitudes toward the self in social, academic, family, and personal areas of experience" (Coopersmith, 2002, p. 1). It can be completed in approximately 10 minutes by children as young as 8 years of age. All items are declarative statements about the self (e.g., "I often feel upset in school" and "I'm pretty sure about myself"), which are answered as either "like me" or "unlike me." Each item is scored a 1 if students respond to negative items as "unlike me" and to positive items as "like me." Items answered "unlike me" for positive items and "like me" for negative items are scored 0 .

Scores are sums of item responses for five self-esteem subscales: General, Social Self-Peers, Home-Parents, SchoolAcademic, and Total Self-Esteem. The Total Self-Esteem score is determined by adding the self-esteem items that are answered in a positive direction. Raw scores range from 0 to 50 , and standardized scores, calculated by multiplying the total raw score by 2 , range from 0 to 100 . In addition, eight items (e.g., "I always do the right thing") used to calculate a Lie Scale (Lie) score are not used to compute the Total score.

Coopersmith (2002) reported internal consistency coefficients ranging between .80 and .92 for Total Self-Esteem across samples of racially, ethnically, and socioeconomically diverse populations. Split-half reliability coefficients for the subscales ranged between .87 and .90 . In the present study, alpha coefficients were as follows: General, .89 (26 items); Social Self-Peers, 72 (eight items); Home-Parents, . 75 (eight items); and School-Academic, . 70 (eight items). Convergent validity was assessed by comparing scores on the CSEI-SF with scores on the behavioral rating scales $(r=.44)$ and the personality inventories $(r=.45)$.

\section{Data Analysis}

Descriptive statistics were computed for all instruments, subscales, and demographic items. Data were analyzed using path analysis as implemented in LISREL (Jöreskog \& Sörbom, 2005). The data were first analyzed using a saturated path model (i.e., $d f_{\text {model }}=0$ ) with perfect model fit. Using the saturated model produces results equivalent to what can be found using multivariate regression analysis (the only difference being the use of maximum likelihood instead of least squares in the estimation process).

One of the advantages of using the path analysis approach is that it allows for later exploratory analyses. This type of exploratory analyses is a process similar to backward elimination in regression analysis, wherein the least significant path (i.e., the path with smallest $z$ score) in the model can be removed. The model is then reestimated and fit is assessed. If a significant decrease in model fit is detected, the process can be stopped. Otherwise, the next least significant path is removed. Although this process is similar to one that could be conducted on separate multiple regression analyses, the path analysis approach uses a true multivariate approach. That is, all the associations (of both dependent and independent variables) are considered simultaneously. In multiple regression analyses, only the associations among the multiple independent variables are considered. Therefore, in path analysis, a change in one part of a model can have an impact on coefficients in another part of the model (Raykov \& Marcoulides, 2006).

The saturated path analysis model is not displayed as a path diagram because a relationship is modeled among all variables. The resulting path diagram is therefore cluttered and difficult to visually interpret. The saturated model was specified as follows:

- Gender was dummy coded and used to predict (i.e., $\gamma$ coefficients were estimated) all other variables in the model.

- Each wellness subscale was included, and these subscales were allowed to be correlated with each other.

- Each self-esteem subscale was included, and these subscales were allowed to be correlated with one another.

- The wellness subscales were not allowed to be correlated with the self-concept subscales.

- Each self-esteem subscale was then predicted (i.e., $\beta$ coefficients were estimated) by each wellness subscale. 
The total scales for wellness and self-esteem were omitted from the analysis so that results could demonstrate the extent to which the individual aspects of both constructs were related to one another. Finally, because of the multiple nonsignificant structural paths, an exploratory analysis was conducted to achieve more specific and meaningful findings.

\section{Results}

The results of the initial path analysis (see Table 2) and subsequent exploratory path analysis (see Table 3 ) led to the final path model shown in Figure 2. This model is equivalent to a series of multiple regressions (Jöreskog \& Sörbom, 2005); hence, readers not familiar with path analysis should interpret the results as multiple regression coefficients. To aid in interpretation, we standardized every variable except gender (set to a mean of 0 and standard deviation of 1) before the analysis. Therefore, a path coefficient represents the change in standard deviation units in $y$ (e.g., academic self-esteem) that occurs with a one standard deviation change in $x$ (e.g., creative wellness). Gender was not standardized, so a path coefficient represents the change in standard deviation units in $y$ (e.g., academic self-esteem) that occurs when the dummy-coded variable changes from 1 to 2 . Because female is coded as 2, a positive coefficient would represent females as higher on the construct being predicted.

Table 2 contains the structural regression coefficients that were estimated. The predicted variables are in the rows; the predictors are in the columns. The wellness variables were predicted only by gender. This analysis is analogous to conducting $t$ tests for gender. The total amount of variance $\left(R^{2}\right)$ is reported only when at least one significant predictor was found. The correlations between the wellness subscales and the self-esteem subscales are omitted because they were not part of the research questions.
There are four statistically significant results shown in Table 2. Coping Self and Social Self wellness (along with contributions from nonsignificant variables) explained 39\% of the variance in General Self-Esteem. Higher levels of Coping Self and Social Self wellness were associated with higher levels of General Self-Esteem. Coping Self and Social Self wellness (along with contributions from nonsignificant variables) explained $25 \%$ of the variance in Social Self-Esteem. Creative Self wellness (along with contributions from nonsignificant variables) explained $26 \%$ of the variance in Social Self-Esteem. Higher levels of Coping Self and Social Self wellness were associated with higher levels of Social SelfEsteem. About 3\% of Essential Self wellness was explained by a gender effect, with females responding with lower levels of Essential Self wellness.

In conducting the exploratory analysis, because a significant decrement-to-model fit was not encountered, we continued the process until there were no more nonsignificant paths to remove. The final model fit was excellent $\left(\chi^{2}=21.52\right.$, $d f=21, p=.43$; root mean square error of approximation $=.01$, comparative fit index $=1.0$, normed fit index $=.99$, and standardized root mean square residual $=.02$ ). Gender, Physical Self wellness, and Essential Self wellness no longer had any significant structural relations with other variables. Therefore, for clarity of results, these variables were dropped from the model; the resulting path model is shown in Figure 2. The structural regression coefficients are summarized in Table 3, following the same format as in Table 2. With these nonsignificant variables removed for clarity of presentation, adjusted model fit was still excellent $\left(\chi^{2}=3.33, d f=4, p=.50\right.$; root mean square error of approximation $<.01$, comparative fit index $=1.0$, normed fit index $=.99$, and standardized root mean square residual $=.02$ ). In the path model, Coping Self and Social Self wellness explained $37 \%$ of the variance in

TABLE 2

Initial Path Analysis Coefficients From Saturated Model $(N=140)$

\begin{tabular}{|c|c|c|c|c|c|c|c|c|c|c|c|c|c|c|c|c|c|c|c|}
\hline \multirow[b]{3}{*}{ Predicted } & \multicolumn{19}{|c|}{ Predictors } \\
\hline & \multicolumn{3}{|c|}{ Gender } & \multicolumn{3}{|c|}{ Creative } & \multicolumn{3}{|c|}{ Coping } & \multicolumn{3}{|c|}{ Social } & \multicolumn{3}{|c|}{ Essential } & \multicolumn{3}{|c|}{ Physical } & \multirow[b]{2}{*}{$R^{2}$} \\
\hline & EC & $S E$ & $z^{n}$ & EC & $S E$ & $z^{a}$ & EC & $S E$ & $z^{n}$ & EC & $S E$ & $z^{n}$ & EC & $S E$ & $z^{a}$ & EC & $S E$ & $z^{n}$ & \\
\hline \multicolumn{20}{|c|}{ Self-esteem ${ }^{b}$} \\
\hline General & -0.24 & 0.14 & -1.72 & 0.05 & 0.10 & 0.48 & 0.47 & 0.08 & 5.75 & 0.18 & 0.08 & 2.13 & -0.08 & 0.07 & -1.12 & 0.09 & 0.08 & 1.16 & 0.39 \\
\hline Social & -0.12 & 0.15 & -0.80 & -0.09 & 0.12 & -0.80 & 0.33 & 0.09 & 3.59 & 0.31 & 0.09 & 3.31 & -0.06 & 0.08 & -0.73 & 0.12 & 0.09 & 1.33 & 0.25 \\
\hline Home & -0.17 & 0.16 & -1.05 & 0.05 & 0.12 & 0.38 & 0.17 & 0.10 & 1.79 & 0.18 & 0.10 & 1.90 & 0.08 & 0.09 & 0.88 & 0.06 & 0.09 & 0.64 & \\
\hline School & -0.03 & 0.15 & -0.17 & 0.42 & 0.11 & 3.64 & 0.17 & 0.09 & 1.84 & -0.08 & 0.09 & -0.85 & -0.01 & 0.08 & -0.12 & 0.05 & 0.09 & 0.53 & 0.26 \\
\hline \multicolumn{20}{|c|}{ 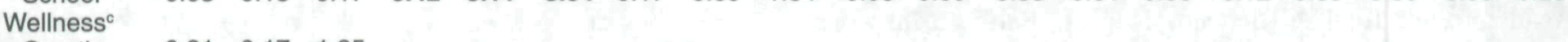 } \\
\hline Creative & -0.31 & 0.17 & -1.85 & & & & & & & & & & & & & & & & \\
\hline Coping & -0.32 & 0.17 & -1.90 & & & & & & & & & & & & & & & & \\
\hline Social & 0.05 & 0.17 & 0.29 & & & & & & & & & & & & & & & & \\
\hline Essential & -0.33 & 0.17 & -2.00 & & & & & & & & & & & & & & & & 0.03 \\
\hline Physical & -0.22 & 0.17 & -1.27 & & & & & & & & & & & & & & & & \\
\hline
\end{tabular}

Note. Significant results are bolded. Total amount of variance $\left(R^{2}\right)$ is reported only when at least one significant predictor was found. EC = estimated coefficient. Wellness subscales: Creative = Creative Self; Coping = Coping Self; Social = Social Self; Essential = Essential Self; Physical = Physical Self. Self-esteem subscales: Social = Social Self-Peers; Home = Home-Parents; School = School-Academic.

aRatio of estimated coefficient to standard error and should be interpreted as a $z$ score. 'DSubscales of the Coopersmith Self-Esteem Inventories-School Form. 'Subscales of the Five Factor Wellness Inventory. 
TABLE 3

Subsequent Path Analysis Coefficients From Saturated Model $(N=140)$

\begin{tabular}{|c|c|c|c|c|c|c|c|c|c|c|}
\hline \multirow[b]{3}{*}{ Predicted } & \multicolumn{9}{|c|}{ Predictors } & \multirow[b]{3}{*}{$R^{e}$} \\
\hline & \multicolumn{3}{|c|}{ Creative } & \multicolumn{3}{|c|}{ Coping } & \multicolumn{3}{|c|}{ Social } & \\
\hline & EC & $S E$ & $z^{a}$ & EC & $S E$ & $z^{n}$ & EC & $S E$ & $z^{\mathrm{a}}$ & \\
\hline \multicolumn{11}{|l|}{ Self-esteem ${ }^{b}$} \\
\hline General & & & & 0.49 & 0.07 & 6.75 & 0.22 & 0.07 & 2.13 & 0.37 \\
\hline Social & & & & 0.29 & 0.08 & 3.61 & 0.29 & 0.08 & 3.69 & 0.23 \\
\hline Home & & & & 0.22 & 0.09 & 2.62 & 0.23 & 0.08 & 2.80 & 0.14 \\
\hline School & 0.36 & 0.08 & 4.41 & 0.18 & 0.09 & 2.04 & & & & 0.23 \\
\hline
\end{tabular}

Note. Significant results are bolded. Predictors are subscales from the Five Factor Wellness Inventory. EC = estimated coefficient. Wellness subscales: Creative = Creative Self; Coping = Coping Self; Social $=$ Social Self. Self-esteem subscales: Social = Social Self-Peers; Home = Home-Parents; School = School-Academic.

a Ratio of estimated coefficient to standard error and should be interpreted as a z score. bSubscales of the Coopersmith Self-Esteem Inventories-School Form.

General Self-Esteem, $23 \%$ of the variance in Social Self-Peers Self-Esteem, and $14 \%$ of the variance in Home-Parents SelfEsteem. In addition, Creative Self and Coping Self wellness explained $23 \%$ of the variance in School-Academic Self-Esteem.

\section{Discussion}

The results of this study provide support for our initial hypothesis that wellness factors are predictive of self-esteem in adolescents. Consistent with the multidimensional nature of both constructs, the relationships found are complex and, particularly in the case of gender, inconsistent with earlier findings about possible gender differences in wellness (see Myers \& Sweeney, 2008). A closer examination of the specific relationships in the exploratory model is useful for counselors both as a foundation for practice and to guide the development of subsequent research studies.
The Coping Self was the sole wellness factor consistently related to all four components of self-esteem. Myers and Sweeney (2005b) defined Coping Self wellness as "the combination of elements that regulate our responses to life events and provide a means for transcending their negative effects" (p. 33). This second-order wellness factor is composed of four third-order factors in the IS-Wel model: Realistic Beliefs, Stress Management, Self-Worth, and Leisure. Although positive relationships with aspects of self-esteem would be anticipated on the basis of the inclusion of the Self-Worth factor, it is noteworthy that the items on the $5 \mathrm{~F}$-Wel differ from those on the CSEI-SF in important ways. The 5F-Wel items assess the extent to which one likes, values, and accepts oneself (e.g., "I like myself in spite of my imperfections") and use a Likert-type response scale that allows for gradations of responses. The CSEI-SF items have a dichotomous response format and assess qualities of self-esteem such as mood states (e.g., "I'm pretty happy"), emotional responses to life events (e.g., "I get upset easily at home"), and self-confidence (e.g., "I'm pretty sure of myself"). Among the 19 items on the Coping Self subscale, only four assess self-worth; thus, it is unlikely that overlap in the constructs of self-esteem and self-worth, as defined by the respective scale authors, could account for the obtained results.

The strong relationships between the Coping Self and all aspects of self-esteem underscore the need for counselors to incorporate all aspects of this factor in interventions with adolescents. It is possible that some components of the Coping Self are more important than others and contribute more to the variance in self-esteem. Future studies are needed to provide more specific information as a foundation for practice.

Adler spoke of the creative self as the combination of attributes that each person forms to make a unique place among others in his or her social interactions (Myers \& Sweeney, 2005c). There are

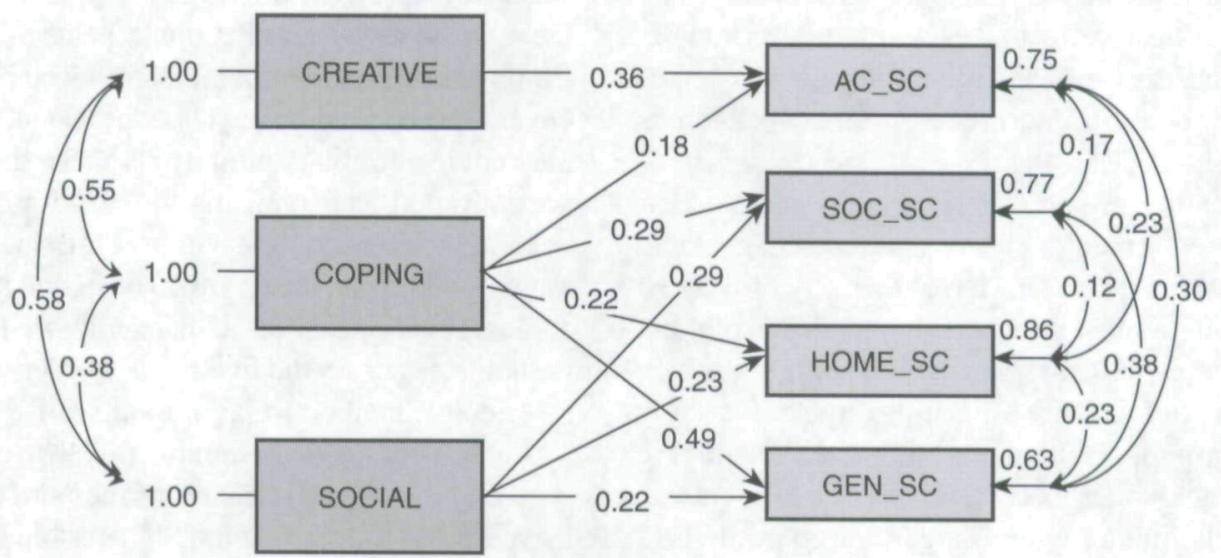

FIGURE 2

Exploratory Path Analysis Results

Note. $N=140 . \chi^{2}=3.33, d f=4, p=.50$; root mean square error of approximation <.01. Wellness subscales (Five Factor Wellness Inventory subscales): CREATIVE = Creative Self; COPING $=$ Coping Self; SOCIAL $=$ Social Self. Self-esteem subscales (Coopersmith Self-Esteem Inventories-School Form subscales): AC_SC = School-Academic, GEN_SC = General; SOC_SC = Social Self-Peers; Home_SC = Home-Parents. 
five third-order factors within this second-order wellness factor: Thinking, Emotions, Control, Positive Humor, and Work. These factors incorporate a variety of attitudes and behaviors necessary for wellness: the need for intellectual stimulation and problem solving on a daily basis; the ability to appropriately express a full range of emotions; belief in one's ability to set and achieve goals; the ability to use humor to resolve the predicaments of life; and, for adolescents, feelings of satisfaction in being able to complete schoolwork tasks and feel valued by others in the school setting. On the basis of the findings, interventions that focus on both Coping and Creative Self wellness may be expected to have a positive effect on School-Academic Self-Esteem, which in turn may promote positive school achievement (Coopersmith, 2002).

The Social Self includes the third-order wellness factors of Friendship and Love. Both nonsexual intimate relationships and healthy family dynamics are integral to this factor (Myers \& Sweeney, 2005b). Social support has been identified in multiple studies as the strongest predictor of positive mental health over the life span (e.g., Lightsey, 1996). The mainstay of this support is family, with healthier families providing the most positive sources of individual wellness. The relationships found between the Social Self and aspects of SelfEsteem, notably Social Self-Peers and Home-Parents, were not surprising and underscore the importance of addressing relationships both at school and home when addressing selfesteem issues among adolescents.

General path analysis guidelines suggest that sample sizes between 100 and 200 are of "medium size" (Kline, 2005, p. 110). Although additional consideration of model complexity might suggest the sample size for this path analysis was small, the findings of significance suggest it was adequate for the current study. A statistical model accounts for small sample sizes through larger standard errors around estimates. With these larger standard errors, a larger effect size is needed to produce statistical significance. Significant effect sizes reported in these results are no more likely to have occurred by chance than by significant effect sizes with a larger sample. Therefore, on the basis of findings of significant effect sizes and the excellent model fit, interpretation of these findings is warranted.

As with all quantitative research, replication with a new sample should be performed to ensure that results are stable and complete. The sample size may have adversely influenced the ability to detect some smaller effects. Additionally, the current participants came from only one school, and given the nature of that school (i.e., private), replication of the study with students from public schools in additional geographic areas is needed. The gender effects, for instance, might not be dropped from the model with a larger and more diverse sample. Gender significantly influenced Essential Self wellness in the first analysis but was removed during the exploratory analysis. Additionally, the exploratory results, as with any exploratory analysis, must be verified with a new sample to ensure that the results are not the result of capitalizing on chance variation in the data set.

\section{Implications for Counselors}

The empirical findings that various wellness factors contribute to the variance in components of self-esteem have implications for counselors working with adolescents. For example, counselors can use the knowledge that the Creative Self is an important contributor to School-Academic Self-Esteem when advocating with teachers and school administrators concerning the need for developmental counseling interventions, because improvements in academic self-esteem have been linked empirically to enhanced school performance and positive academic outcomes (Coopersmith, 2002). More explicitly, school counselors can incorporate assessments and measures into their school counseling program evaluation initiatives that monitor the relationships between students' changes in self-esteem and academic performance, as a result of participating in a classroom guidance or small-group counseling intervention focusing on wellness. This is particularly relevant in the era of No Child Left Behind where school counselors, specifically, are being asked to integrate their comprehensive developmental school counseling programs into the overall academic success of the entire student body (Dahir \& Stone, 2009). Consequently, the results from this study can be used to design wellness school counseling interventions, which are likely to have a positive effect on self-esteem components.

Villalba and Myers (2008) demonstrated the effectiveness of wellness interventions in a developmental counseling program with elementary school students. This program could be modified for use with adolescents as well, with the findings from the current study justifying the usefulness of wellness-based initiatives with adolescents. The IS-Wel is a holistic model that students can learn to promote understanding of their overall wellness. In addition, the model includes individual factors that may compose the focus of guidance groups in classes or as extracurricular opportunities. On the basis of the current findings, the wellness factors that offer the most potential for affecting aspects of self-esteem are the Coping and Social Self factors, followed by the Creative Self. Given limited time for psychoeducational groups, counselors may choose to focus initially on these three factors. If time is not limited, as is typically the case for counselors working outside of school settings, counseling interventions (including individual and group work) designed to help children and adolescents hone in on their overall wellness strengths and weaknesses across the five second-order wellness factors are an effective method for addressing self-esteem issues.

In the process of designing wellness-oriented counseling interventions, an examination of the third-order factors in the IS-Wel model can be helpful. Students might be presented with detailed definitions of the factors (see Myers \& Sweeney, 2005a) and asked to explore the relevance of these aspects of wellness in their own lives. The method in which definitions are shared with youngsters should be developmentally appropriate, perhaps using visual or creative arts mechanisms with younger children (e.g., photographs of different leisure activities and sporting activities 
or asking children to draw five healthy snacks they like to eat) and written or experiential activities with adolescents (e.g., composing an essay on what it means to be a good friend or asking participants to keep a journal of daily exercise for 1 month to monitor their stress management and self-care). In addition to designing specific interventions to enhance each wellness component, counselors can engage students in the process of cocreating healthy activities and personal wellness plans. Wellness plans should be designed from a systemic and longitudinal perspective, encouraging youngsters to make connections between wellness and self-esteem within the contexts of school, home, community, and so on, and to continually explore these connections by establishing short-term and long-term goals. As with specific interventions, wellness plans also should be designed with the child's developmental level in mind, conceivably incorporating four or five second-order factors for older children over the course of an academic year, or focusing on only one or two third-order factors (e.g., nutrition or self-care) for young children over the course of 2 weeks.

Wellness requires an emphasis on personal choice and responsibility, and wellness choices are self-empowering. Thus, teaching students about wellness will both prepare and empower them for making healthy choices that can have a positive impact over their entire life span (Dixon Rayle \& Hartwig Moorhead, 2005). It is hoped that these choices also will affect self-esteem, creating a positive cycle of both greater wellness and more positive feelings of worth during a critical developmental period.

\section{Conclusion}

The connection between wellness and self-esteem has been established in the education, counseling, and adolescent development literature. This study provides more specific information concerning the link between wellness and self-esteem and provides data to support specific types of wellness counseling interventions most likely to have a positive effect on adolescent self-esteem. Additional studies are needed to support and extend the current findings. Counselors choosing to create wellness counseling programs based on this study are encouraged to document their strategies and results as models for others. Outcome studies demonstrating increased academic success as a result of wellness counseling interventions may convince administrators and teachers of the vital need for wellness interventions in the schools.

\section{References}

Bosson, J. K., Brown, R. P., Zeigler-Hill, V., \& Swann, W. B., Jr. (2003). Self-enhancement tendencies among people with high explicit self-esteem: The moderating role of implicit self-esteem. Self \& Identity, 2, 169-187.

Bronfenbrenner, U. (2007). A constant frame of reference for sociometric research. Sociometry, 6, 363-397.

Choate, L. H., \& Smith, S. L. (2003). Enhancing development in 1st-year college student success courses: A holistic approach. Journal of Humanistic Counseling, Education and Development, 42, 178-193.
Coopersmith, S. (2002). Coopersmith Self-Esteem Inventories: Manual. Palo Alto, CA: Mindgarden.

Dahir, C. A., \& Stone, C. B. (2009). School counselor accountability: The path to social justice and systemic change. Journal of Counseling \& Development, 87, 12-20.

Dixon Rayle, A., \& Hartwig Moorhead, H. J. (2005), Research on adolescent wellness. In J. E. Myers \& T. J. Sweeney (Eds.), Counseling for wellness: Theory, research, and practice (pp. 67-75). Alexandria, VA: American Counseling Association.

González, M., Casas, F., \& Coenders, G. (2007). A complexity approach to psychological well-being in adolescence: Major strengths and methodological issues. Social Indicators Research, 80, 267-295.

Hattie, J. A., Myers, J. E., \& Sweeney, T. J. (2004). A factor structure of wellness: Theory, assessment, analysis, and practice. Journal of Counseling \& Development, 82, 354-364.

Jöreskog, K., \& Sörbom, D. (2005). LISREL for Windows [Computer software]. Lincolnwood, IL: Scientific Software International.

Kernis, M. H. (2003). Toward a conceptualization of optimal selfesteem. Psychological Inquiry, 14, 1-26.

Keyes, C. L. M. (2006). Mental health in adolescence: Is American's youth flourishing? American Journal of Orthopsychiatry, 76, 395-402.

Kline, R. B. (2005). Principles and practice of structural equation modeling (2nd ed.). New York, NY: Guilford Press.

Kostanski, M., \& Gullone, E. (1998). Adolescent body image dissatisfaction: Relationships with self-esteem, anxiety, and depression controlling for body mass. Journal of Child Psychology and Psychiatry, 2, 255-262.

Lightsey, O. R., Jr. (1996). What leads to wellness? The role of psychological resources in well-being. The Counseling Psychologist, 24, 589-735. doi: $10.1177 / 0011000096244002$

MacPhee, A. R., \& Andrews, J. J. W. (2006). Risk factors for depression in early adolescence. Journal of Adolescence, 41, 435-466.

Makinson, L., \& Myers, J. E. (2003). Wellness: An alternative paradigm for violence prevention. Journal of Humanistic Counseling, Education and Development, 42, 165-177.

Marshall, S. K. (2001). Do I matter? Construct validation of adolescents' perceived mattering to parents and friends. Journal of Adolescence, 24, 473-490.

McLoed, J. D., \& Owens, T. J. (2004). Psychological well-being in the early life course: Variations by socioeconomic status, gender, and race/ethnicity. Social Psychology Quarterly, 67, 257-278.

Myers, J. E., \& Sweeney, T. J. (2005a). The Five Factor Wellness Inventory manual. Palo Alto, CA: Mindgarden.

Myers, J. E., \& Sweeney, T. J. (2005b). The Indivisible Self: An evidencebased model of wellness. In J. E. Myers \& T. J. Sweeney (Eds.), Counseling for wellness: Theory, research, and practice (pp. 29-37). Alexandria, VA: American Counseling Association.

Myers, J. E., \& Sweeney, T. J. (2005c). The Wheel of Wellness. In J. E. Myers \& T. J. Sweeney (Eds.), Counseling for wellness: Theory, research, and practice (pp. 15-28). Alexandria, VA: American Counseling Association.

Myers, J. E., \& Sweeney, T. J. (2008). Wellness counseling: The evidence base for practice. Journal of Counseling \& Development, 86, 482-493. 
Myers, J. E., Sweeney, T. J., \& Witmer, J. M. (2000). The Wheel of Wellness counseling for wellness: A holistic model for treatment planning. Journal of Counseling \& Development, 78, 251-266.

Niregi, K. (2006). Attributional style and self-esteem of female juvenile delinquents. Japanese Journal of Counseling Science, 39, 99-112.

Powell, K. C. (2004). Developmental psychology of adolescent girls: Conflicts and identity issues. Education, 125, 77-87.

Raykov, T., \& Marcoulides, G. A. (2006). A first course in structural equation modeling. Mahwah, NJ: Erlbaum.

Robins, R. W., Trzesniewski, K. H., Tracy, J. L., Gosling, S. D., \& Potter, J. (2002). Global self-esteem across the life span. Psychology and Aging, 17, 423-434. doi:10.1037//0882-7974.17.3.423

Searcy, Y. D. (2007). Placing the horse in front of the wagon: Toward a conceptual understanding of the development of self-esteem in children and adolescents. Child and Adolescent Social Work Journal, 24, 121-131.

Sewell, T. E. (1985). Review of Coopersmith Self-Esteem Inventories. In J. V. Mitcell Jr. (Ed.), Ninth mental measurements yearbook. Available from http://buros.unl.edu/buros/jsp/reviews. jsp?item $=07000701$
Stinson, D. A., Logel, C., Zanna, M. P., Holmes, J. G., Cameron, J. J., Wood, J. V., \& Spencer, S. J. (2008). The cost of lower selfesteem: Testing a self- and social-bonds model of health. Journal of Personality and Social Psychology, 94, 412-428.

Sweeney, T. J., \& Witmer, J. M. (1991). Beyond social interest: Striving toward optimum health and wellness. Individual Psychology, 47, 527-540.

Tanigoshi, H., Kontos, A. P., \& Remley, T. P., Jr. (2008). The effectiveness of individual wellness counseling on the wellness of law enforcement officers. Journal of Counseling \& Development, 86, 64-74.

Twenge, J. M., \& Campbell, W. K. (2001). Age and birth cohort differences in self-esteem: A cross-temporal meta-analysis. Personality and Social Psychology Review, 5, 321-344.

Villalba, J. A., \& Myers, J. E. (2008). Effectiveness of wellness-based classroom guidance in elementary school settings: A pilot study. Journal of School Counseling, 6(9). Retrieved from http://www. jsc.montana.edu/articles/v6n9.pdf

Wastlund, E., Norlander, T., \& Archer, T. (2001). Exploring crosscultural differences in self-concept: A meta-analysis of the SelfDescription Questionnaire. The Journal of Comparative Social Science, 35, 280-302. 
Copyright of Journal of Counseling \& Development is the property of American Counseling Association and its content may not be copied or emailed to multiple sites or posted to a listserv without the copyright holder's express written permission. However, users may print, download, or email articles for individual use. 